\section{Prevalence and causes of visual impairment among the elderly in Nantong, China}

\begin{abstract}
Purpose To investigate the prevalence and causes of visual impairment among adults aged 60 and above in Nantong city, China.
\end{abstract}

Methods A stratified random sampling was used to select the people from eight communities in Xinchengqiao administrative sub-district of Nantong. The eye examinations were conducted at the community activity centres. The definitions of visual impairment were based on the pinhole visual acuity (low vision: visual acuity $<6 / 18$ to $3 / 60$ in the better eye; blindness: visual acuity $<3 / 60$ in the better eye). Prevalence of visual impairment based on presenting visual acuity was also calculated. Both univariate and multiple analysis were used to do the statistics.

Results A total of $3040(90.69 \%)$ out of 3352 enumerated subjects participated in the survey. The prevalence of blindness and low vision based on the pinhole visual acuity was $1.35 \%$ (presenting, $1.32 \%$ ) and $1.84 \%$ (presenting, $6.05 \%$ ) respectively. The prevalence of blindness and low vision grew up exponentially with age $\left(R^{2}=0.9993\right.$, $\mathrm{F}=1385.84, P=0.0007 ; R^{2}=0.9949, \mathrm{~F}=195.65$, $P=0.0051)$ and down with increasing education level (score test for trend of odds: $\left.\chi^{2}=30.35, P=0.0000 ; \chi^{2}=22.31, P=0.0000\right)$, and was higher among women than men $\left(\operatorname{LR} \chi^{2}=9.62, P=0.0019 ;\right.$ LR $\chi^{2}=5.14$, $P=0.0234)$.

Conclusions Blindness and low vision were prevalent in the urban area of China, especially in the elderly women, with cataract the most common cause in the Chinese elderly. Therefore, our study highlights an urgent necessity for launching some programs for blindness and low vision prevention, especially on the early treatment of cataract.
Eye (2008) 22, 1069-1075; doi:10.1038/eye.2008.53; published online 9 May 2008

Keywords: visual impairment; blindness; low vision; cataract; prevalence

\section{Introduction}

Visual impairment is a global public health problem. The prevalence of visual impairment is affected by many factors and active prevention and treatment measures are helpful to reduce the risk factors. On the basis of the latest statistics, China is home to one of the world's largest population of blind people, an estimated 6.6 million. Currently the aging process in China is the fastest in the world. According to World Health Organization, the people over 60 are defined as elder (WHO, Health Statistics Annual 1987). The number of Chinese above the age of 60 will increase from the current 147 million to 174 million in 2010, representing about one-eighth (12.5\%) of the total population at that time. And in 2020, the number is expected to reach 243 million, accounting for one-sixth (16.7\%), according to the figures from China National Committee of Aging. ${ }^{1}$ With the rapid growing number of aging people in China, the age-related eye diseases are becoming more and more severe. In view of such a growing number of people, an elaborative survey on the prevalence of visual impairment in China is not only helpful to know the real situation, but also useful to launch some effective eye disease prevention and treatment campaigns.

Nantong city is located in Jiangsu, an eastern Province of China. It covers an area of $8001 \mathrm{~km}^{2}$ with a population of 7.8 million and its general economic level is above the average in China. In the 1950s, Nantong initiated eye-disease
${ }^{1}$ Department of Ophthalmology, Affiliated Hospital, Nantong University, Nantong, Jiangsu Province, China

2Zhongshan Ophthalmic Center, Sun Yat-sen University, Guangzhou, Guangdong Province, China

${ }^{3}$ Department of Biostatistics, School of Public Health,

Nantong University,

Nantong, Jiangsu Province, China

Correspondence: H Guan, Department of Ophthalmology, Affiliated Hospital, Nantong University, Nantong 226001, Jiangsu, China Tel: + 86051385052341 E-mail: Jannetlee130@ yahoo.com.cn or Guanhj@ ntu.edu.cn

Received: 15 November 2007

Accepted in revised form: 4 February 2008 Published online: 9 May 2008 
prevention and treatment programs that took trachoma as the major endeavour. From the 1980s, with the principal cause of blindness has shifted to cataract, the city again launched a large-scale basic eyecare programs. Due to its fruitful effort, Nantong was honoured as the first model city in China for blindness prevention. ${ }^{2}$ In order to know the current situation of blindness and visual impairment in eastern China, and to evaluate the efficacy of blindness prevention and treatment in recent years, a sampling survey was conducted among Nantong elderly.

\section{Materials and methods}

The target population was the entire group of people aged 60 or above residing in Xinchengqiao administrative sub-district, lying partially in the urban and partially in the suburban areas. The sampling could be representative of the population structure in Nantong. A randomly stratified sampling survey was conducted in Xinchengqiao, which includes 14 densely populated communities with a population of 57843 (National Census Data 2000), in Chongchuan district of Nantong city.

Based on the results from the survey in Shunyi County, $\mathrm{China}^{3}$ the prevalence of blindness (age $\geqslant 60$ ) was $2.8 \%$. The sample size was selected to achieve an estimate of 95\% confidence level for the prevalence of bilateral blindness (visual acuity $<3 / 60$ in both eyes) within a $\pm 25 \%$ error bound. Assuming that the sampling design effect was 1.25 and that the response rate was $90 \%$, the required sample size for this study would be 2964 . About $11.1 \%$ of the residents in Xinchengqiao were aged 60 or older, so 26702 residents should be sampled to achieve the required sample size. Therefore, eight communities, with an estimated population of 30248 in total, were randomly selected from the 14 communities.

The fieldwork was carried out from July 2003 to October 2003 by two groups of researchers. Each group consisted of two qualified ophthalmologists, one ophthalmic assistant and one enumerator. The overall survey was supervised by a chief doctor. Prior to the formal survey, a training course and a pilot study were conducted so that the whole survey could be finished successfully. The pilot data were used for assessing interobserver agreements in visual acuity measurements and diagnosis. The data from the pilot survey were not formally reported in this article.

All residents aged 60 or above on the residence roster in Xinchengqiao sub-district were enumerated. Namely, the information of the residents, including their name, gender, age, and address, was verified according to the residence data. Written notices were sent to each enumerated resident, and those who were out were verified at the time of departure. All the residents were mobilised to undergo the eye examination at the specific site at an appointed time. For those disabled who were not convenient to go to the examine site, the ophthalmologists visited their homes to perform necessary examinations with medical instruments, such as HEINE HSL100 ${ }^{\circledR}$ Hand-held Slit Lamp (HEINE Ltd., Munich, Germany), Proview Eye Pressure Monitor (Bausch \& Lomb Incorporated, NY, USA), direct ophthalmoscope (66vision Tech Co., Ltd., Suzhou, China), and so on.

Distant visual acuity was measured for each eye separately using an illuminated logMAR (logarithm of minimum angle of resolution) chart at $4 \mathrm{~m}$ distance, and the data was recorded as the smallest line with one or no errors. Presenting visual acuity was measured with the participants' habitual distance correction. The bestcorrected vision was tested with a pinhole spectacle for those with acuity $<0.5 \log$ MAR units $(6 / 18,0.3)$. Since it was very hard to conduct a satisfactory refraction examination for all subjects in such a large-scale epidemiological survey, this survey, as has been adopted in the Shunyi survey ${ }^{3}$ and Hong Kong study, pre-supposed that the pinhole vision was the best-corrected vision.

External eye and anterior segment were examined by the ophthalmologist using a slitlamp biomicroscope (66vision Tech Co., Ltd., Suzhou, China). Intraocular pressure was measured with a Goldmann applanation tonometer (66vision Tech Co., Ltd., Suzhou, China). Fundus examinations, including vitreous, retina, and optic disc, were conducted using a direct ophthalmoscope (66vision Tech Co., Ltd., Suzhou, China).

Dilation was carried out for those whose presenting visual acuity was $<0.5 \operatorname{logMAR}$ units $(6 / 18,0.3)$ and remained $<0.5 \log$ MAR units $(6 / 18,0.3)$ with a pinhole spectacle, and whose condition was not attributable to corneal disease. Pupils were not dilated in those eyes that have shallow anterior chamber checked by the slitlamp using van Herick technique. ${ }^{5}$

For eyes with pinhole visual acuity $<0.5 \log$ MAR units $(6 / 18,0.3)$, a principal cause of impairment/blindness was diagnosed and assigned by the ophthalmologists. According to uniformly pre-defined criteria, the participants who were suspected to have conditions such as glaucoma (criteria were as follows: family history of glaucoma, previous diagnosis of glaucoma, shallow anterior chamber, intraocular pressure $>21 \mathrm{~mm} \mathrm{Hg}$, cup-disc ratio of $\geqslant 0.5$, or asymmetry in cup-disc ratio between the two eyes of 0.2 or more), other optic nerve lesion, high visual pathway lesion, and significant macular/retinal pathological lesion were allowed to receive automated visual field examinations by a 
Humphrey visual field analyzer (Carl Zeiss, Jena, Germany). The examinations were repeated if the ophthalmologist considered the results unreliable.

The International Classification of Diseases, 10th edition (ICD-10) ${ }^{6}$ defines visual impairment as a best-corrected vision of $<6 / 18(0.3)$ in the better eye. Visual impairment has been categorised to bilateral blindness and low vision, the visual acuity is, in the better eye with the best correction, $<3 / 60(0.05)$ and $<6 / 18(0.3)$ but not $<3 / 60$ (0.05), respectively. Presenting visual acuity was also used to describe visual impairment within the survey.

In this study, the cause of visual impairment in the less affected eye was taken as the principal cause for participants with bilateral visual impairment, even if two or more conditions might have existed in the same participant. ${ }^{7}$ If cataract and the retinal abnormality coexisted, and removal of cataract would not restore vision, the cause of blindness was considered to be the retinal abnormality. If dense cataract was present that prevented any view of the retinal abnormality, and if no signs suggestive of any other causes of visual loss were present, the cause of blindness was considered to be cataract. If refractive error was due to cataract, then even if the vision improved with refraction, the cause of blindness was considered cataract rather than refractive error because the former was the underlying cause. ${ }^{8}$ Refractive errors were defined as visual impairment that improved to $6 / 18(0.3)$ or better with a pinhole. Retinal diseases were defined as retinal abnormalities caused by dystrophy, degeneration, or diabetic retinopathy. Glaucoma was considered the main cause of visual deterioration in case of an enlarged cup-disc ratio or cup-disc ratio asymmetry between the two eyes along with an intraocular pressure of $>21 \mathrm{~mm} \mathrm{Hg}$.

The Medical Ethics Committee of Nantong University had approved the study protocol. An informed oral consent for each subject was obtained before enrolment. The survey followed the tenets of the Declaration of Helsinki.

Inter-observer comparison of visual acuity measurements between the ophthalmic assistants (one from each of the two groups) was carried out during the pilot study. Of the 148 examined eyes 22 had pinhole visual acuity $<0.5 \log$ MAR units $(6 / 18,0.3)$. In accordance with visual acuity, the following three categories were defined: (1) those with pinhole visual acuity $\geqslant 0.5 \log$ MAR units $(6 / 18,0.3) ;(2)<0.5 \log$ MAR units $(6 / 18,0.3)$ to $\geqslant 1.3 \log \mathrm{MAR}$ units $(3 / 60,0.05)$; and (3) $<1.3 \log$ MAR units $(3 / 60,0.05)$. In terms of the categories, there was an agreement in 146 of the 148 eyes $(\kappa=0.98)$. Inter-examiner comparisons were also carried out between the project director and each of the two group ophthalmologists for the recognition of lens opacity and in the assignment of a principal cause of impairment for those eyes with visual acuity $<6 / 18$. For lens opacity diagnosis, the $\kappa$-statistic was 0.89 for one pair (212 eyes examined, 142 identified as not having lens opacity by both observers) and 0.85 for another pair (180 eyes examined, 124 with agreement on no lens opacity). For the inter-examiner comparisons on the principal cause of impairment, the $\kappa$ was 0.82 for one pair (63 eyes with visual acuity $<6 / 18)$ and 0.86 for another pair $(70$ eyes).

All survey data were sequentially entered into the EpiData (version 3.0, EpiData Association) database twice, independently by two data clerks. Two data sets were compared and inconsistent values were doublechecked and corrected if necessary. All data analyses were performed using Stata software (version 8.0). ${ }^{9}$ The prevalence of visual impairment was calculated as percentage of the total population and stratified by each of age, gender, and education level. An exponential function with two parameters, which could be expressed as prevalence $=b_{1} \times b_{2}^{a g e}$ was used to fit the increasing trend of prevalence with age, which has been classified as a categorical variable (age 60-79, 70-79, 80-89, and $90+)$. To assess the associations of age, sex, and education level with visual impairment, adjusted odd ratios and their $95 \%$ confidence intervals (95\% CIs) were estimated using multiple logistic regression.

\section{Results and conclusion}

Among the 3352 eligible enumerated subjects, 3040 were examined (90.69\% response rate), which was slightly higher than the anticipated $90 \%$.

Those enumerated subjects who were absent in the eye examinations were categorised as follows: temporarily leaving the surveyed area (112) or severe illness (71); refusing the survey because of their busy schedule (78); thinking that there was no significance for old people to undergo the eye examination (23), and worrying about the eye examination imposing harm to their eyes (28). Taken together, total 3040 out of 3352 eligible enumerated subjects underwent the examination. The examination rate was $90.69 \%$.

The characteristics and distribution of age, sex, and education level of the enumerated and examined residents are listed in Table 1 . The prevalence of blindness and low vision was down with increasing education level (score test for trend of odds: $\chi^{2}=30.35$, $\left.P=0.0000 ; \chi^{2}=22.31, P=0.0000\right)$ and it was higher among women than among men $\left(\operatorname{LR} \chi^{2}=9.62, P=0.0019\right.$; LR $\left.\chi^{2}=5.14, P=0.0234\right)$.

When using presenting vision, the prevalence of bilateral blindness and low vision was $1.32 \%(95 \% \mathrm{CI}$, $0.94-1.79 \%$ ) and $6.05 \%$ (95\% CI, 5.23-6.96\%), respectively. When pinhole visual acuity was used, the prevalence of 
Table 1 Enumerated examined study subjects and prevalence of bilateral blindness and low vision by age, sex, and education level

\begin{tabular}{|c|c|c|c|c|c|c|c|c|c|}
\hline & \multicolumn{2}{|c|}{ Enumerated } & \multicolumn{3}{|c|}{ Examined } & \multicolumn{2}{|c|}{ Blindness } & \multicolumn{2}{|c|}{ Low vision } \\
\hline & No. & $\%$ & No. & $\%$ & $\%$ Examined & No. & $\%$ & No. & $\%$ \\
\hline \multicolumn{10}{|l|}{ Age (years) } \\
\hline 60-69 & 1948 & 58.11 & 1787 & 58.78 & 91.74 & 10 & 0.56 & 11 & 0.62 \\
\hline $70-79$ & 1080 & 32.22 & 997 & 32.80 & 92.31 & 15 & 1.50 & 17 & 1.71 \\
\hline $80-89$ & 280 & 8.35 & 225 & 7.40 & 80.36 & 9 & 4.00 & 21 & 9.33 \\
\hline $90+$ & 44 & 1.32 & 31 & 1.02 & 70.45 & 7 & 22.58 & 7 & 22.58 \\
\hline \multicolumn{10}{|l|}{ Sex } \\
\hline Male & 1519 & 45.32 & 1369 & 45.03 & 90.13 & 9 & 0.66 & 17 & 1.24 \\
\hline Female & 1833 & 54.68 & 1671 & 54.97 & 91.16 & 32 & 1.92 & 39 & 2.33 \\
\hline \multicolumn{10}{|l|}{ Education level } \\
\hline None & 503 & 15.00 & 455 & 14.97 & 90.46 & 22 & 4.80 & 26 & 5.68 \\
\hline Elementary school & 802 & 23.93 & 684 & 22.50 & 85.29 & 10 & 1.47 & 12 & 1.76 \\
\hline Junior high school & 713 & 21.27 & 664 & 21.84 & 93.13 & 2 & 0.30 & 4 & 0.60 \\
\hline Senior high school & 718 & 21.42 & 682 & 22.43 & 94.99 & 4 & 0.59 & 7 & 1.03 \\
\hline College and above & 616 & 18.38 & 555 & 18.26 & 90.10 & 3 & 0.54 & 7 & 1.26 \\
\hline Total & 3352 & 100.00 & 3040 & 100.00 & 90.69 & 41 & 1.35 & 56 & 1.84 \\
\hline
\end{tabular}

Table 2 Association of bilateral blindness and low vision with age, sex, and education level

\begin{tabular}{|c|c|c|c|c|}
\hline & \multicolumn{2}{|c|}{ Blindness } & \multicolumn{2}{|c|}{ Low vision } \\
\hline & $O R^{\mathrm{a}}$ & $95 \% C I$ & $O R^{\mathrm{a}}$ & $95 \% C I$ \\
\hline \multicolumn{5}{|l|}{ Age (years) } \\
\hline $60-69$ & 1 & & 1 & \\
\hline $70-79$ & 2.18 & $0.96-4.97$ & 2.54 & $1.17-5.53$ \\
\hline $80-89$ & 4.68 & $1.80-12.22$ & 13.18 & $5.99-29.00$ \\
\hline $90+$ & 29.02 & $9.49-88.72$ & 33.42 & $11.25-99.22$ \\
\hline \multicolumn{5}{|l|}{ Sex } \\
\hline Male & 1 & & 1 & \\
\hline Female & 1.83 & $0.80-4.19$ & 1.53 & $0.79-2.93$ \\
\hline \multicolumn{5}{|l|}{ Education level } \\
\hline None & 1 & & 1 & \\
\hline Elementary school & 0.42 & $0.19-0.93$ & 0.44 & $0.21-0.91$ \\
\hline Junior high school & 0.12 & $0.03-0.53$ & 0.22 & $0.07-0.66$ \\
\hline Senior high school & 0.24 & $0.07-0.77$ & 0.42 & $0.17-1.06$ \\
\hline College and above & 0.26 & $0.07-0.97$ & 0.56 & $0.21-1.48$ \\
\hline
\end{tabular}

aOR, adjusted odds ratio (multiple logistic regression).

bilateral low vision dropped from 6.05 to $1.84 \%$ (95\% CI, 1.39-2.39\%), however, bilateral blindness increased from 1.32 to $1.35 \%$ (95\% CI, $0.97-1.83 \%$ ). Table 1 also shows the prevalence of blindness and low vision based on pinhole visual acuity by age, sex, and education level.

In the multiple logistic regression model, bilateral blindness and bilateral low vision were regarded as the outcome, and sex, age, and education level as the covariates, which were included in the form of a collection of dummy variables. The adjusted odds ratios and their corresponding 95\% CIs based on pinhole visual acuity are shown in Table 2 . It was indicated that the subjects aged 70-79, 80-89, and $90+$ had a higher risk of having bilateral low vision than those in the 60-69 age group. Similarly, the subjects aged 80-89 and $90+$ had a higher likelihood of having bilateral blindness than those in the 60-69 age group, while the subjects aged 70-79 to 60-69 had no statistical significance. Bilateral blindness and low vision was 1.83 and 1.53 times as likely to occur among women and men. However, both of which were not of statistical significance.

However, the adjusted odds ratios of bilateral blindness showed statistical significance. Subjects with no education (none) had a higher likelihood of catching bilateral blindness than those with higher education levels. The adjusted odds ratio of bilateral low vision for subjects with higher education versus the subjects with no education (none) showed no statistical significance.

The relation between age and bilateral blindness, and that between age and bilateral low vision could be fitted to exponential functions (Figure 1). As shown in the figure the prevalence of either bilateral blindness or low vision increased exponentially with the increasing age $\left(R^{2}=0.9993, \mathrm{~F}=1385.84, P=0.0007 ; R^{2}=0.9949\right.$, $\mathrm{F}=195.65, P=0.0051)$.

The principal causes of bilateral blindness and bilateral low vision are presented in Table 3 . From the table, it is evident that cataract was the primary cause for people with bilateral blindness. Of the 41 subjects 26 had cataract diagnosed as the cause of bilateral blindness. Therefore, there was $63.41 \%(26 / 41)$ of subjects whose visual acuity could be restored through cataract surgery.

The principal causes for unilateral blindness (pinhole visual acuity $<3 / 60$ in only one eye) or unilateral low vision ( $<6 / 18$ to $3 / 60$ in only one eye) based on the data 

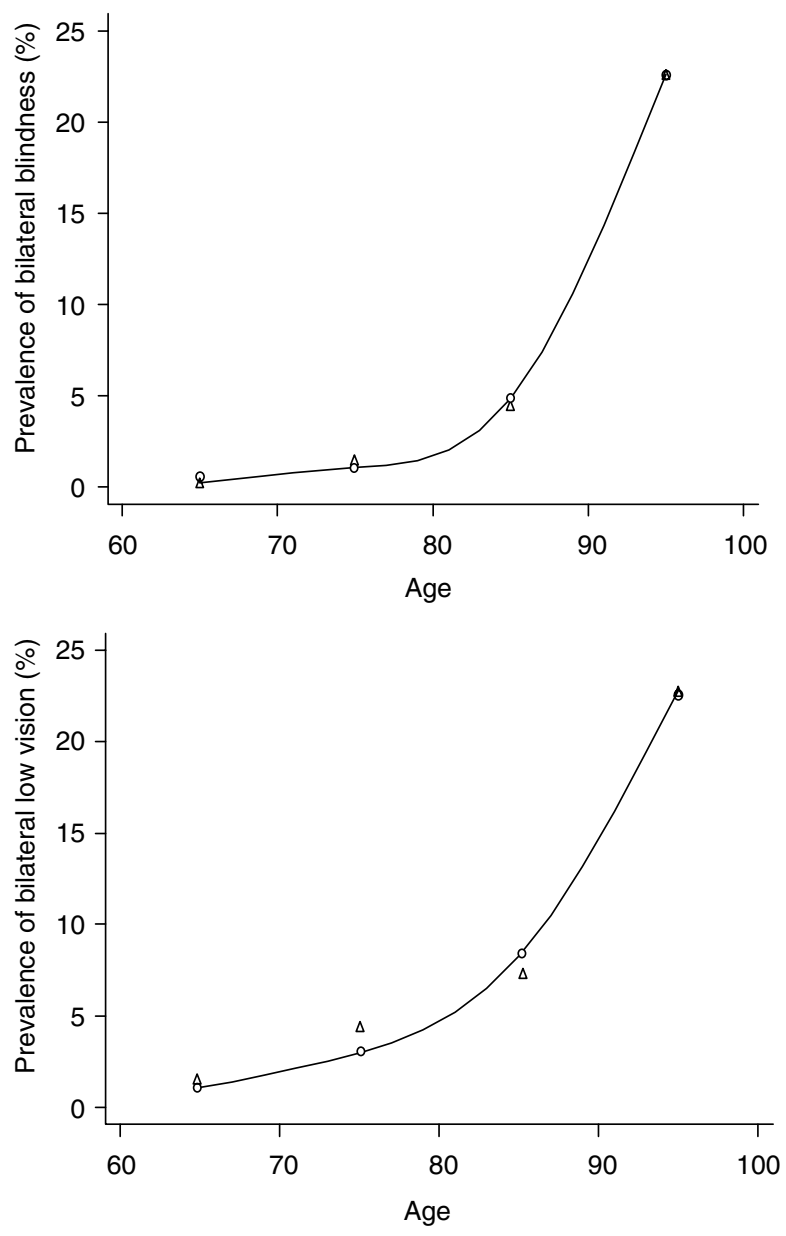

Figure 1 Prevalence of bilateral blindness in relation to age (top). The prevalence of bilateral blindness was $0.0000102 \times 1.166268^{\text {age }}(\mathrm{F}=1385.84, P=0.0007)$, and the correlation factor of the fitting was 0.9993 . Prevalence of bilateral low vision in relation to age (bottom). The prevalence of bilateral low vision was $0.0014411 \times 1.107134^{\text {age }}(\mathrm{F}=195.65, P=0.0051)$, and the correlation factor of the fitting was 0.9949 . of individual eyes are presented in Table 3. Of the 70 eyes with retinal abnormalities, 36 were age-related macular degeneration, and 22 were diagnosed as vascular retinopathy (including diabetic retinopathy). Besides, 6 of 14 eyes with corneal opacities were attributed to trachoma.

\section{Discussion}

The prevalence and causes of visual impairment in an urban Chinese population were assessed in this study. Our results showed that the prevalence of blindness and visual impairment increased with age, especially among those aged above 70 . It was probably attributable to the high prevalence of age-related eye diseases such as cataract and macular degeneration, and the lack of appropriate early treatment of the related diseases. Visual impairment was more prevalent among women and illiterate subjects. This is very likely attributable to their lack of access to medicare because of the lower education levels and socio-economic status.

Prevalence of blindness and its causes reported from population-based studies in different regions of China and different countries are presented in Table 4 . The prevalence of blindness among those aged 60 or over was lower than that in $\operatorname{Lasa}^{12}(8.27 \%)$ but higher than in Beijing $^{10}(0.62 \%)$. The principal cause for blindness in most regions was cataract, except in Shanghai, where the principal cause was macular degeneration. ${ }^{11}$ In addition to the blindness prevention and treatment programs, the difference was likely attributable to different socioeconomic status in China, which made the cataract surgery more affordable for patients in Shanghai.

The global prevalence of blindness is estimated to be $0.7 \%$, ranging from 0.3 to $0.5 \%$ in the developed countries. In the developing countries, it is $>1.5 \% .{ }^{15,16}$

Table 3 Distribution of principal causes for bilateral and unilateral blindness and low vision

\begin{tabular}{|c|c|c|c|c|c|}
\hline \multirow[t]{2}{*}{ Principal cause } & \multicolumn{2}{|c|}{ Bilateral $^{\mathrm{a}}$} & \multicolumn{3}{|c|}{ Unilateral $^{\mathrm{b}}$} \\
\hline & Blindness no. (\%) & Low vision no. (\%) & Blindness no. (\%) & Low vision no. (\%) & Total no. (\%) \\
\hline Cataract & $26(63.41)$ & $39(69.64)$ & $50(45.04)$ & $69(47.59)$ & 119 (46.48) \\
\hline Retinal abnormalities & $9(21.95)$ & $6(10.71)$ & $30(27.03)$ & $40(27.59)$ & $70(27.35)$ \\
\hline Refractive error & $4(9.76)$ & $5(8.93)$ & $8(7.21)$ & $15(10.34)$ & $23(8.98)$ \\
\hline Corneal opacity & $1(2.44)$ & $2(3.57)$ & $8(7.21)$ & $6(4.14)$ & $14(5.48)$ \\
\hline Glaucoma & $0(0.00)$ & $1(1.79)$ & $0(0.00)$ & $6(4.14)$ & $6(2.34)$ \\
\hline Amblyopia & $0(0.00)$ & $1(1.79)$ & $0(0.00)$ & $4(2.75)$ & $4(1.56)$ \\
\hline Optic (absent/atrophy) & $0(0.00)$ & $0(0.00)$ & $4(3.60)$ & $0(0.00)$ & $4(1.56)$ \\
\hline Other/undeterminable & $1(2.44)$ & $2(3.57)$ & $11(9.91)$ & $5(3.45)$ & $16(6.25)$ \\
\hline Total & $41(100.00)$ & $56(100.00)$ & $111(100.00)$ & $145(100.00)$ & $256(100.00)$ \\
\hline
\end{tabular}

${ }^{a}$ Data are given as number (percentage) of persons.

${ }^{b}$ Data are given as number (percentage) of eyes, vision categories are defined by the pinhole visual acuity in only one eye. Unilateral blindness $<3 / 60$; unilateral low vision $<6 / 18$ to $\geqslant 3 / 60$. 
Table 4 Prevalence of blindness and its causes reported from population-based studies in different regions

\begin{tabular}{|c|c|c|c|c|c|}
\hline Region (Country) & $\begin{array}{l}\text { Sample } \\
\text { size }\end{array}$ & $\begin{array}{l}\text { Age } \\
\text { (years) }\end{array}$ & Definition & $\begin{array}{l}\text { Prevalence } \\
\quad(\%)\end{array}$ & Main causes (\%) \\
\hline Nantong (China) & 3040 & $\geqslant 60$ & $<3 / 60^{\mathrm{b}}$ & 1.35 & $\begin{array}{l}\text { Cataract (63.41), retinal abnormalities }(21.95) \text {, } \\
\text { refractive error }(9.76) \text {, corneal opacity }(2.44)\end{array}$ \\
\hline Hong Kong ${ }^{4}$ (China) & 3441 & $\geqslant 60$ & $<6 / 60^{\mathrm{a}}$ & 1.80 & Cataract (51.7), macular degeneration (27.1), glaucoma (7.1) \\
\hline Beijing $^{10}$ (China) & 4409 & $>40$ & $<20 / 400^{\mathrm{b}}$ & 0.34 & $\begin{array}{l}\text { Cataract (40), degenerative myopia (13.3), } \\
\text { corneal opacity (13.3) }\end{array}$ \\
\hline Shanghai ${ }^{11}$ (China) & 7499 & $\geqslant 60$ & $<3 / 60^{\mathrm{b}}$ & 0.71 & $\begin{array}{l}\text { Degenerative retinopathy (39.6), cataract (17.0), corneal opacity (17.0), } \\
\text { retinal angiopathy (11.3), pigmentosa degeneration (1.9) }\end{array}$ \\
\hline Lasa $^{12}$ (China) & 3071 & $\geqslant 40$ & $<6 / 60^{\mathrm{a}}$ & 3.20 & Corneal opacity (4.6), optic atrophy (4.1) \\
\hline Doumen $^{13}$ (China) & 5342 & $\geqslant 50$ & $<3 / 60^{\mathrm{a}}$ & 2.67 & $\begin{array}{l}\text { Cataract (44.9), Corneal opacity (16.4), opticatrophy (10.7), } \\
\text { refractive error (7.1), glaucoma (5.9) }\end{array}$ \\
\hline Taiwan $^{14}$ (China) & 1361 & $\geqslant 65$ & $<20 / 400^{\mathrm{b}}$ & 0.59 & $\begin{array}{l}\text { Cataract (41.7), myopic macular degeneration (12.5), } \\
\text { age-related macular degeneration (10.4) }\end{array}$ \\
\hline \multirow[t]{2}{*}{$\begin{array}{l}\text { Copenhagen }^{7} \\
\text { (Denmark) }\end{array}$} & 1000 & $60-80$ & $<20 / 400^{b}$ & 0.53 & $\begin{array}{l}\text { Age-related macular degeneration }(40) \text {, glaucoma }(40) \text {, } \\
\text { retinitis pigmentosa (20) }\end{array}$ \\
\hline & & & $<20 / 200^{\mathrm{b}}$ & 1.06 & $\begin{array}{l}\text { Age-related macular degeneration (40), glaucoma (10), cataract (10), } \\
\text { pigmentosa degeneration (10), excessive myopic degeneration (10) }\end{array}$ \\
\hline $\begin{array}{l}\text { Andhra Pradesh } \\
\text { (India) }\end{array}$ & 10213 & All & $<6 / 60^{a}$ & 1.84 & $\begin{array}{l}\text { Cataract (44), refractive error (16.3), retinal disease (10.9), } \\
\text { glaucoma (8.2), corneal disease (7.1) }\end{array}$ \\
\hline $\operatorname{Oman}^{17}$ (Oman) & 11417 & All & $<3 / 60^{\mathrm{a}}$ & 1.1 & Cataract (30.5), trachomatous corneal opacities (23.7), glaucoma (11.5) \\
\hline \multirow[t]{2}{*}{ Tehran $^{18}$ (Iran) } & 4565 & All & $<3 / 60^{\mathrm{b}}$ & 0.28 & $\begin{array}{l}\text { Cataract (36.0), macular degeneration (20.0), amblyopia (10.7), } \\
\text { corneal opacity (6.7) }\end{array}$ \\
\hline & & & $<3 / 60^{\mathrm{a}}$ & 0.39 & $\begin{array}{l}\text { Refractive error (33.6), cataract (25.4), macular degeneration (12.7), } \\
\text { amblyopia (8.2) }\end{array}$ \\
\hline $\begin{array}{l}\text { Bangladesh }^{19} \\
\text { (Bangladesh) }\end{array}$ & 12782 & $\geqslant 30$ & $<3 / 60^{\mathrm{a}}$ & 1.53 & Cataract (79.6), uncorrected aphakia (6.2), macular degeneration (3.1) \\
\hline $\begin{array}{l}\text { Bioko }^{20} \\
\text { (Equatorial Guinea) }\end{array}$ & 3218 & All & $<3 / 60^{b}$ & 3.2 & $\begin{array}{l}\text { Cataract (61.3), macular affection (25.3), optic atrophy (16), } \\
\text { glaucoma (13.3) }\end{array}$ \\
\hline Salisbury ${ }^{21}$ (USA) & 2519 & $65-84$ & $<20 / 200^{b}$ & 0.83 & $\begin{array}{l}\text { Age-related macular degeneration (42.9), opticatrophy (14.2), glaucoma } \\
\text { (9.5), Diabetic retinopathy (9.5), non-ARMD retinal diseases (9.5) }\end{array}$ \\
\hline
\end{tabular}

${ }^{\text {aPresenting visual acuity. }}$

${ }^{\mathrm{b}}$ Best-corrected visual acuity.

Though the prevalence estimates were affected by the population structure, examined subjects, definition of vision acuity, and methodologies used in surveys, the blindness affecting a large number of people in the developing countries should not be neglected. We should address that although our survey showed that the prevalence of blindness was lower than Hong Kong, a developed city, we could not say that blindness was not a problem for Nantong or the neighbouring places anymore because the survey only represented the present status of Nantong. With rapid change of city structure and the coming of aging, the blindness problems may deteriorate in the future. Therefore, Nantong should still be cautious and keep launching the intervention programs.

The WHO and the International Agency for the Prevention Blindness launched a global initiative, 'Vision 2020: the Right to Sight', to eliminate avoidable blindness by the year $2020 .^{22,23}$ Currently, cataract, retinal diseases, and refractive error are major causes for blindness in China. Cataract and refractive error are considered as avoidable causes of blindness. Therefore, there is an urgent need for early cataract detection and cataract surgery. In view of this, our survey highlighted the need to develop comprehensive eyecare programs (eg early treatment of cataract) for the increasing number of elderly people, with a special emphasis on prevention of blindness in women and in those with lower education levels.

\section{Acknowledgements}

We thank the Bureau of Public Health, Disabled Persons' Federation of Nantong City and the government of the Xinchengqiao sub-district for their support and cooperation in facilitating the implementation of this research. We also thank Haihong Shi, Zhenggao Xie, Qinjin Chen, Jianquan Sun, Lili Yin, and Xiaoming Gao for data collection, and Wei Liu and Xiaohu Gu for data entry.

\section{References}

1 Flaherty JH, Liu ML, Ding L, Dong B, Ding Q, Li X et al. China: the aging giant. J Am Geriatr Soc 2007; 55(8): 1295-1300. 
2 Guan H, Gong Q, Miao B, Chen B, Cao J, Liu H et al. Inquires about methods of primary eye care and prevention of blindness. Zhonghua Yan Ke Za Zhi 2001; 37: 9-11.

3 Zhao J, Jia L, Sui R, Zhang C, Xiang L, Zhang H et al. Prevalence of blindness among adults aged 50 years or above in Shunyi county of Beijing. Zhonghua Yan Ke Za Zhi 1999; 35: 341-347.

4 Michon JJ, Lau J, Chan WS, Ellwein LB. Prevalence of visual impairment, blindness, and cataract surgery in the Hong Kong elderly. Br J Ophthalmol 2002; 86: 133-139.

5 Van Herick W, Shaffer RN, Schwartz A. Estimation of width of angle of anterior chamber: incidence and significance of the narrow angle. Am J Ophthalmol 1969; 68: 626-629.

6 ICD-10. International Statistical Classification of Diseases and Related Health Problems, 10th Revision. In: Johnson GJ, Minassian DC, Weale R (eds). The Epidemiology of Eye Disease. Chapman \& Hall Medical: London, 1998; 8-30.

7 Buch H, Vinding T, La Cour M, Nielsen NV. The prevalence and causes of bilateral and unilateral blindness in an elderly urban Danish population. The Copenhagen City Eye Study. Acta Ophthalmol Scand 2001; 79: 441-449.

8 Dandona L, Dandona R, Srinivas M, Giridhar P, Vilas K, Prasad MN et al. Blindness in the Indian State of Andhra Pradesh. Invest Ophthalmol Vis Sci 2001; 42: 908-916.

9 StataCorp. Stata Statistical Software: Release 8.0. Stata Corporation: College Station, TX, 2001.

10 Xu L, Wang Y, Li Y, Wang Y, Cui T, Li J et al. Causes of blindness and visual impairment in urban and rural areas in Beijing: the Beijing Eye Study. Ophthalmology 2006; 113: 1134-1141.

11 Zou H, Zhang X, Xu X, Wang W, Li G, Yu H et al. An epidemiological survey of low vision and blindness of senile persons in Beixinjing blocks, Shanghai. Zhonghua Yan Ke Za Zhi 2002; 38: 744-746.

12 Hou B, De J, Wu H, Gesang D, Bu P, Qiangba S et al. Prevalence of blindness among adults aged 40 years or above in Linzhou county of Lasa. Zhonghua Yan Ke Za Zhi 2002; 38: 589-593.
$13 \mathrm{Xu} \mathrm{J}, \mathrm{He} \mathrm{M}, \mathrm{Wu} \mathrm{K}, \mathrm{Li} \mathrm{S}$. The vision distribution and causes of blindness in elderly population in Doumen county. Zhonghua Yan Ke Za Zhi 1999; 35: 348-351.

14 Hsu WM, Cheng CY, Liu JH, Tsai SY, Chou P. Prevalence and causes of visual impairment in an elderly Chinese population in Taiwan: the Shihpai Eye Study. Ophthalmology 2004; 111: 62-69.

15 Thylefors B, Negrel AD, Pararajasegaram R, Dadzie KY. Global data on blindness. Bull World Health Organ 1995; 73: 115-121.

16 Thylefors B, Negrel AD, Pararajasegaram R, Dadzie KY. Available data on blindness (update 1994). Ophthalmic Epidemiol 1995; 2: 5-39.

17 Khandekar R, Mohammed AJ, Negrel AD, Riyami AA. The prevalence and causes of blindness in the Sultanate of Oman: the Oman Eye Study (OES). Br J Ophthalmol 2002; 86: 957-962.

18 Fotouhi A, Hashemi H, Mohammad K, Jalali KH. The prevalence and causes of visual impairment in Tehran: the Tehran Eye Study. Br J Ophthalmol 2004; 88: 740-745.

19 Dineen BP, Bourne RR, Ali SM, Huq DM, Johnson GJ. Prevalence and causes of blindness and visual impairment in Bangladeshi adults: results of the National Blindness and Low Vision Survey of Bangladesh. Br J Ophthalmol 2003; 87: 820-828.

20 Moser CL, Martin-Baranera M, Vega F, Draper V, Gutiérrez J, Mas J. Survey of blindness and visual impairment in Bioko, Equatorial Guinea. Br J Ophthalmol 2002; 86: 257-260.

21 Muñoz B, West SK, Rubin GS, Schein OD, Quigley HA, Bressler SB et al. Causes of blindness and visual impairment in a population of older Americans: The Salisbury Eye Evaluation Study. Arch Ophthalmol 2000; 118: 819-825.

22 Pararajasegaram R. VISION 2020 - the right to sight: from strategies to action. Am J Ophthalmol 1999; 128: 359-360.

23 Thylefors B. A global initiative for the elimination of avoidable blindness. Am J Ophthalmol 1998; 125: 90-93. 